\title{
In vivo evaluation of mutant selection window of cefquinome against Escherichia coli in piglet tissue-cage model
}

\author{
Bingxu Zhang, Xiaoyan Gu, Yafei Li, Xiaohong Li, Mengxiao Gu, Nan Zhang, Xiangguang Shen \\ and Huanzhong Ding*
}

\begin{abstract}
Background: The resistance of cephalosporins is significantly serious in veterinary clinic. In order to inhibit the bacterial resistance production, the mutant selection window (MSW) hypothesis with Escherichia coli (E. coli) ATCC 25922 exposed to cefquinome in an animal tissue-cage model was investigated.

Results: Localized infection with E. coli was established in piglets, and the infected animals were administrated intramuscularly with various doses and intervals of cefquinome to provide antibiotic concentrations below the $\mathrm{MIC}_{99}$, between the $\mathrm{MIC}_{99}$ and the mutant prevention concentration (MPC), and above the MPC. E. coli lost susceptibility when drug concentrations fluctuated between the lower and upper boundaries of the window, which defined in vitro as the $\mathrm{MIC}_{99}(0.06 \mu \mathrm{g} / \mathrm{mL})$ and the MPC $(0.16 \mu \mathrm{g} / \mathrm{mL})$ respectively. For PK/PD parameters, there were no mutant selection enrichment when $\mathrm{T}>\mathrm{MIC}_{99}$ was $\leq 25 \%$ or $\mathrm{T}>\mathrm{MPC}$ was $\geq 50 \%$ of administration interval. When $\mathrm{T}>\mathrm{MIC}_{99}$ was $>25 \%$ and $\mathrm{T}>\mathrm{MPC}$ was $<50 \%$ of administration interval, resistance selection was observed. When $\mathrm{AUC}_{24} \mathrm{~h} / \mathrm{MIC}_{99}$ and $\mathrm{AUC}_{24} \mathrm{~h} / \mathrm{MPC}$ were considered, the mutant selection window extended from $32.84 \mathrm{~h}$ to $125.64 \mathrm{~h}$ and from $12.83 \mathrm{~h}$ to $49.09 \mathrm{~h}$, respectively.

Conclusions: These findings demonstrate that the MSW exists in vivo for time-dependent antimicrobial agents, and its boundaries fit well with those determined in vitro. Maintenance of antimicrobial concentrations above the MPC for $>50 \%$ of administration interval is a straightforward way to restrict the acquisition of resistance in this tissue cage model. This situation was achieved with daily intramuscular doses of $1 \mathrm{mg}$ cefquinome/kg body weight.
\end{abstract}

Keywords: Tissue-cage models, Mutant selection window, Cefquinome, Piglets

\section{Background}

The development of bacterial resistance has resulted from a variety of factors, including drug overuse and drug misuse [1], both in the environment and during therapy [2]. Even the commonly accepted treatment strategy of killing susceptible pathogens contributes to the problem by allowing selective amplification of resistant mutants during the treatment [3]. According to a proposed hypothesis, resistant mutants selectively amplify at antibiotic concentrations within the mutant selection window (MSW), drug concentrations between the boundary of $\mathrm{MIC}_{99}$

\footnotetext{
* Correspondence: hzding@scau.edu.cn

National Reference Laboratory of Veterinary Drug Residues (SCAU), College of Veterinary Medicine, South China Agricultural University, Guangzhou 510642, China
}

2014 Zhang et al.; licensee BioMed Central. This is an Open Access article distributed under the terms of the Creative Commons Attribution License (http://creativecommons.org/licenses/by/4.0), which permits unrestricted use, distribution, and reproduction in any medium, provided the original work is properly credited. The Creative Commons Public Domain Dedication waiver (http://creativecommons.org/publicdomain/zero/1.0/) applies to the data made available in this article unless otherwise stated. (inhibition of $99 \%$ of the cells) and mutant prevention susceptible single-step mutant subpopulation) [4].

The mutant selection window hypothesis was initially proposed using agar plate assays [5], and then explored in several in vitro or in vivo model [6-11]. However, as far as we know, the time-dependent drugs such as cephalosporin were rarely reported. Cefquinome is a fourth generation broad-spectrum cephalosporin antibiotic, which was developed solely for veterinary use and approved for the treatment of respiratory tract disease, acute mastitis and footrot in cattle, calf septicaemia, respiratory diseases in pigs and metritis-mastitis-agalactia syndrome in sow $[12,13]$. In order to reduce the occurring of cefquinome resistance and even the resistance gene transmission between herd 
and human, the study of mutant selection window is urgent which could be used as a framework for the design of dosage regimen of cefquinome therapy.

Localized infection is particularly suitable for determination the mutant selection window hypothesis in in vivo [4]. One feasible system is the tissue-cage infection model $[4,14]$, which used a tissue-cage with holes on its surface implanted surgically into subcutaneous tissue of an animal. In piglets body, the surface of the cage becomes encapsulated by connective tissue 2-4 weeks after implantation, and the interior is filled with tissue-cage fluid. Bacterial cultures are injected into the cage and remained there until eliminated by host defenses and antimicrobial treatment.

In this study, above $10^{10} \mathrm{CFU}$ of E. coli ATCC 25922 were injected into the tissue-cages implanted in piglets, and various doses and intervals of cefquinome were administered intramuscularly. The objective was to validate that the resistant mutants would be selected predominantly when drug concentrations maintained inside a concentration window, the boundaries of which determined by agar plate assays. It is hoped that this model would have the capability to provide a clear demonstration of the mutant selection window in vivo and support arguments for how antimicrobial dosage regimens adjustment could severely restrict the amplification and enrichment of resistant mutant for cefquinome.

\section{Methods}

\section{Antimicrobials and chemicals}

Penicillin, as a sodium salt for injection, and cefquinome for injection were purchased from Hebei Yuanzheng Pharmaceutical Co., Ltd., P.R. China. Cefquinome standard was from China Institute of Veterinary Drugs Control, Beijing, P.R. China. Acetonitrile and formic acid (chromatography grade) were from Fisher Scientific.

\section{$\mathrm{MIC}_{99}, \mathrm{MIC}$, and MPC determination}

E. coli strain ATCC 25922 stored at $-70 \mathrm{C}$ was grown in Mueller-Hinton broth or on Mueller-Hinton agar. $\mathrm{MIC}_{99}$ and MPC were determined as described elsewhere [15]. Briefly, for $\mathrm{MIC}_{99}$, bacterial cultures were grown overnight $(\geq 10 \mathrm{~h})$ in the constant temperature oscillation incubator at $37 \mathrm{C}, 220 \mathrm{r} / \mathrm{min}$, normal atmosphere, serially diluted, and approximately $10^{6}$ cells were applied to agar plates containing various concentrations of cefquinome. After incubation at $37 \mathrm{C}$ for $16-18 \mathrm{~h}$, bacterial colonies were counted, and the fraction relative to the bacterial inoculum was calculated. Drug concentration that inhibited growth by $99 \%$ was defined as $\mathrm{MIC}_{99}$. For MPC, above $10^{10}$ cells were applied to multiple cefquinomecontaining agar plates. After incubation at $37 \mathrm{C}$ for a total of $96 \mathrm{~h}$ and the examination of the appearance of colonies every $24 \mathrm{~h}, \mathrm{MPC}$ was recorded as the lowest antibiotic concentration at which no colonies grew on an agar plate. The $\mathrm{MIC}_{99}$ and MPC were determined in the five independent experiments.

\section{Tissue-cage infection model}

Healthy castrated cross-bred piglets (Duroc Landrace Yorkshire),weight ranging from 25 to $30 \mathrm{~kg}$, were housed individually and fed antibiotic-free food twice a day. Water was available ad libitum. The experimental protocol was approved by the Committee on the Ethics of animals of South China Agricultural University (Approval number 2013-01; 15 March 2013).

The tissue-cages were made in-house from platinumcured medical grade silicone tubing (Medical silicon, SF Medical; Beijing Jingcheng Chuangye Medical Instrument Co., Ltd., Beijing, P.R. China) and modified slightly from similar cages described by Sidhu et al. [16]. Briefly, the dimensions of the tissue-cages were of $65 \mathrm{~mm}$ length, $18 \mathrm{~mm}$ external diameter and $13 \mathrm{~mm}$ internal diameter. Each cage had 24 identical holes and each hole has a surface area of $9.6 \mathrm{~mm}^{2}$; the total exchange surface area was $2.3 \mathrm{~cm}^{2}$.

Two tissue-cages were implanted subcutaneously in each animal, one on either side of the neck approximately equidistant from the jugular vein and spinal cord under aseptic conditions. Surgical insertion was carried out under deep sedation (pentobarbital sodium) and local infiltration anaesthesia (procainamide hydrochloride injection) in piglets. After surgery, the piglets were treated with intramuscular penicillin $(160000 \mathrm{IU} / \mathrm{kg})$ twice a day for 3-5 days to prevent infection. The nonsteroidal anti-inflammatory drug (NSAID) was provided for analgesia in post-operation simultaneously. By 4 weeks after implantation, each tissue-cage had become sealed with a thin layer of connective tissue and had been filled with clear, yellowish tissue-cage fluid. Above $10^{10} \mathrm{CFU}$ of exponentially growing E. coli ATCC 25922 culture was concentrated in $1 \mathrm{~mL}$ of saline and injected into each tissue-cage. Two days after infection, $0.5 \mathrm{~mL}$ of tissuecage fluid was withdrawn from each cage for a viablebacteria count. Piglets having above $10^{8} \mathrm{CFU} / \mathrm{mL}$ viable bacterial cells in tissue-cage fluid were treated with various doses and intervals of cefquinome.

\section{Pharmacokinetic measurements}

Eighteen piglets were randomly allocated to 7 administration groups and treated at $0.1,0.2,0.4,0.8$, or $1.0 \mathrm{mg} / \mathrm{kg}$ of body weight once a day ( $24 \mathrm{~h}$ interval) or 0.2 and 0.4 $\mathrm{mg} / \mathrm{kg}$ of body weight twice a day (12 h interval). 0.1, 0.8, $1.0 \mathrm{mg} / \mathrm{kg}$ groups had 2 piglets and 4 tissue cages of each group. $0.2,0.4 \mathrm{mg} / \mathrm{kg}$ (12 h and $24 \mathrm{~h}$ interval) groups had 3 piglets and 6 tissue cages of each group, which had one more piglet compared to $0.1,0.8,1.0 \mathrm{mg} / \mathrm{kg}$ groups respectively because these two dosages easily induced 
resistant mutation. And this series of dosages were determined by recommended dose which was $2 \mathrm{mg}$ cefquinome $/ \mathrm{kg}$ body weight in intramuscularly once daily for 3-5 days [13] and pre-experiments data (not provided). Cefquinome were administrated intramuscularly (intragluteal muscles) for consecutive 5 times beginning on the $3^{\text {rd }}$ day after infection with $E$. coli ATCC 25922 for every piglet in administration groups. The control group, three piglets, received sterile physiological saline $(1 \mathrm{~mL})$ simultaneously in the same way. Tissue-cage fluid $(0.5 \mathrm{~mL})$ was collected from the cage at $1,3,6,9,12$, and $24 \mathrm{~h}$ after each administration in group with $24 \mathrm{~h}$ interval. For groups with $12 \mathrm{~h}$ interval, samples were collected at 1, 3, 6, 9, $12 \mathrm{~h}$ after each administration. Fluid samples were clarified by centrifugation at $3000 \mathrm{~g}$ for $10 \mathrm{~min}$ and stored at $-20 \mathrm{C}$.

The concentrations of cefquinome was determined using an Agilent 1200 series high performance liquid chromatography and an Agilent 6400 triple quadrupole mass spectrometer equipped with an electrospray ionization source (HPLC-MS/MS, Agilent Technologies, USA). The chromatographic separation was achieved on a Phenonenex BDS $\mathrm{C}_{18}$ column (150 mm $2 \mathrm{~mm}$; internal diameter, $5 \mu \mathrm{m}$, Phenomenex Technologies) at 40C with a thermostat column oven (Agilent 1200 series, Agilent Technologies). The mobile phase consisted of solution A (water with $0.1 \%$ formic acid, $\mathrm{V} / \mathrm{V}$ ) and solution $\mathrm{B}$ (acetonitrile) at $0.25 \mathrm{~mL} / \mathrm{min}$ flow rate. The gradient elution was: $0-1 \mathrm{~min}$, $5 \% \mathrm{~B}$; $1-5.5 \mathrm{~min}, 60 \% \mathrm{~B}$; $5.5-10 \mathrm{~min}, 5 \% \mathrm{~B}$. The injection volume was $5 \mu \mathrm{L}$.

A calibrated curve was constructed by adding a known amount of cefquinome to blank tissue-cage fluid over concentrations ranged from $0.001 \mu \mathrm{g} / \mathrm{mL}$ to $1 \mu \mathrm{g} / \mathrm{mL}$. The lower limit of quantification (LLOQ) of cefquinome was $5 \mathrm{ng} / \mathrm{mL}$. The recoveries of cefquinome in tissue-cage fluid were 94.2 7.34\% (mean standard deviation, SD, $n=5)$. The coefficients of variability (CV\%) were all $<10 \%$ for both intra-assay and inter-assay variation.

Pharmacokinetic/pharmacodynamic (PK/PD) indices such as $\mathrm{T}>\mathrm{MIC}_{99}, \mathrm{~T}>\mathrm{MPC}, \mathrm{AUC} / \mathrm{MIC}_{99}, \mathrm{AUC} / \mathrm{MPC}$, $\mathrm{C}_{\max } / \mathrm{MIC}_{99}, \mathrm{C}_{\max } / \mathrm{MPC}$ were calculated according to a noncompartmental analysis using WinNonlin programme (version 6.1, Pharsight Corporation, Mountain View, CA, USA). The liner trapezoidal rule was used to calculate the area under the concentration-time curve (AUC). All $\mathrm{PK} / \mathrm{PD}$ indices calculations referred to the $12 \mathrm{~h}$ and $24 \mathrm{~h}$ dosing interval immediately following the fifth injection after finishing administration using the cefquinome concentrations in tissue cage fluid.

\section{Loss of susceptibility to cefquinome}

Potential loss of susceptibility was monitored in tissuecage fluid (0.5 mL/cage) obtained daily before and during the cefquinome treatment (after every administration) and 24 and $48 \mathrm{~h}$ after the termination of treatment.
To amplify cultures, half of each sample was incubated overnight in drug-free Mueller-Hinton broth, and then the MIC was determined with the CLSI [17] agar dilution method. The other half of each sample was serially diluted with sterile physiological saline and applied to agar either lacking drug or containing cefquinome at $1 \mathrm{MIC}$ of the starting culture. After incubation at 37C for 24-48 h, colonies were calculated, and the fraction of mutants in the population was calculated.

Resistant mutants (growing on 1 the MIC of cefquinomecontaining agar) were also chosen randomly from samples that had cefquinome concentrations predominantly in the lower, middle, or upper part of the selection window with $12 \mathrm{~h}$ or $24 \mathrm{~h}$ interval administration. Single colonies of these mutants were passaged 5 times on drug-free agar, and the MIC to cefquinome was then determined.

\section{Statistical analysis}

Fisher s exact test was used for statistical analysis of the $\mathrm{PK} / \mathrm{PD}$ data, with an infected but untreated set of piglets (3 piglets, 6 tissue-cages) as a control. $\mathrm{P}<0.05$ was considered to be statistically significant.

\section{Results}

\section{Bacteria count in tissue-cage model}

Two perforated tissue-cages were implanted into each piglet. When above $10^{10} \mathrm{CFU}$ bacteria were injected into an implanted cage, no severe illness or distress occurred during a 10-day observation. Bacterial concentrations remained constant at about $10^{8} \mathrm{CFU} / \mathrm{mL}$ when piglets were treated intramuscularly for 5 times with sterile physiological saline once or twice daily.

Administration of cefquinome at $0.1 \mathrm{mg} / \mathrm{kg}$ at $24 \mathrm{~h}$ interval slightly reduced bacterial numbers compared to the control during the trial. Administration of cefquinome at 0.2 and $0.4 \mathrm{mg} / \mathrm{kg}$ at $24 \mathrm{~h}$ interval observably reduced bacterial numbers for the first 4 administrations, but bacterial growth was observed later during treatment and during post-treatment. Administration of cefquinome at 0.8 and $1.0 \mathrm{mg} / \mathrm{kg}$ at $24 \mathrm{~h}$ interval caused bacterial numbers to decrease throughout treatment and remain low during the growth recovery phase (Figure 1).

\section{Cefquinome concentrations}

The values of $\mathrm{MIC}, \mathrm{MIC}_{99}$, and MPC were $0.064 \mu \mathrm{g} / \mathrm{mL}$, $0.06 \mu \mathrm{g} / \mathrm{mL}$, and $0.16 \mu \mathrm{g} / \mathrm{mL}$ in present study, respectively. Cefquinome concentrations, determined in samples of tissue-cage fluid collected at various time points over several days, are shown in Figure 2 (panels A1-A8). There were totally 34 tissue cages analyzed and another 2 tissue cages were excluded because of bacterial pollution. And the cefquinome concentrations shown for each of the 8 groups were the means of the concentrations from all animals/ tissue cage fluids selected for those groups. The boundaries 


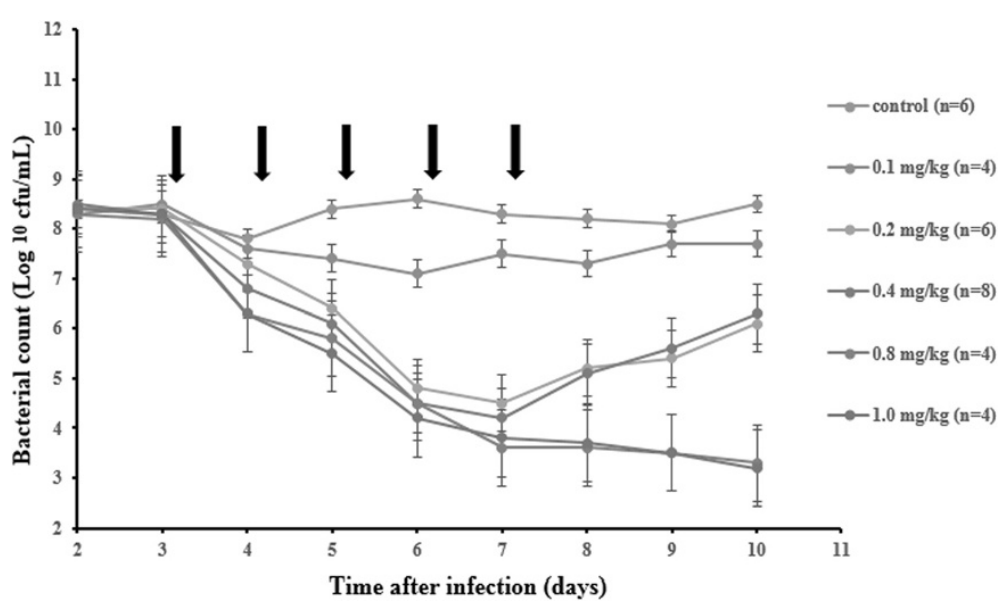

Figure 1 Effect of cefquinome dose on bacterial inhibition in the tissue-cage model. Tissue-cage implantation and Escherichia coli ATCC 25922 infection were done as described in Materials and Methods. Three days after infection, various doses $(0,0.1,0.2,0.4,0.8$, or $1.0 \mathrm{mg} / \mathrm{kg}$ of body weight, each piglet has tissue-cages) of cefquinome were administered intramuscular once daily for 5 days (indicated by the arrow). Bacterial colony-forming units in tissue-cage fluid was monitored at $24 \mathrm{~h}$ intervals beginning 1 day before the initiation of cefquinome in treatment and ending 2 days after the termination of cefquinome treatment.

of the mutant selection window were determined to be $0.06 \mu \mathrm{g} / \mathrm{mL}\left(\mathrm{MIC}_{99}\right)$ and $0.16 \mu \mathrm{g} / \mathrm{mL}(\mathrm{MPC})$ by agar plate assays, which were the average values determined in the five independent experiments. There are 8 groups (A1-A8) to display the different classifications (lower, higher, partially inside, totally inside) of cefquinome concentrations based on the MSW boundary.

\section{MICs and mutant fraction}

Samples of E. coli ATCC 25922 in tissue-cage fluid after treatment with various doses were examined for susceptibility to cefquinome. Increases in MICs were readily observed (Figure 2, panels B3-B8) when cefquinome concentrations were partially or totally inside the selection window (Figure 2, panels A3-A8).

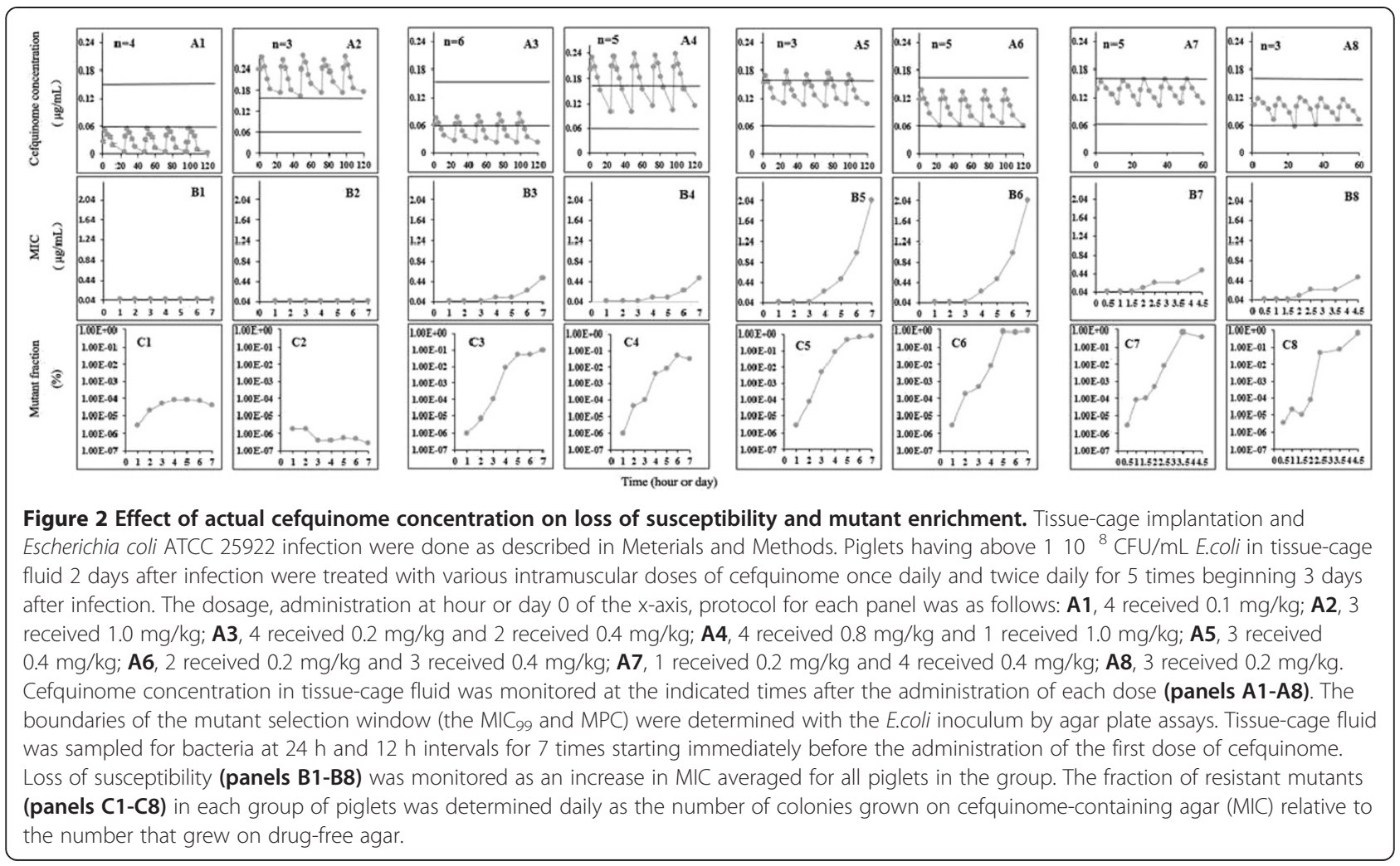


When cefquinome concentrations maintained either below the $\mathrm{MIC}_{99}$ (Figure 2, panel A1) or above the MPC (Figure 2, panel A2), no MIC increase, either during (days 0-5) or after therapy (days 6-7), was observed (Figure 2, panels B1 and B2). When cefquinome concentrations overlapped the lower window boundary $\left(\mathrm{MIC}_{99}\right)$ and the $\mathrm{C}_{\max }$ was lower than the middle concentration $(0.11 \mu \mathrm{g} / \mathrm{mL})$ of the MSW during treatment (Figure 2, panel A3), decreased susceptibility (MIC increase) was detected in 1 of 6 cages and the MIC increased to $0.512 \mu \mathrm{g} / \mathrm{mL}$ at day 7 (Figure 2, panel B3). When cefquinome concentrations crossed the upper boundary of the window (MPC) and the $C_{\min }$ was higher than the middle concentration of the MSW during treatment (Figure 2, panel A4), loss of susceptibility was detected in 1 of 5 cages and the MIC also increased to $0.512 \mu \mathrm{g} / \mathrm{mL}$ at day 7 (Figure 2, panel B4). As drug concentrations were over the $\mathrm{MIC}_{99}$ and $\mathrm{T}>\mathrm{MPC}$ did not exceed $25 \%$ of interval, susceptibility decreased in 8 of 8 cages and the MIC increased to $2.048 \mu \mathrm{g} / \mathrm{mL}$ at day 7 (Figure 2, panels B5 and B6), regardless of the mean concentration located into the lower (Figure 2, panel A6) or upper (Figure 2, panel A5) part of the selection window. In addition, cefquinome susceptibility decreased in all 8 cages and the MIC increased to $0.512 \mu \mathrm{g} / \mathrm{mL}$ at day 5 (Figure 2, panels B7 and B8) in the condition of $12 \mathrm{~h}$ interval with drug concentrations approximately the same with the condition of $24 \mathrm{~h}$ interval (Figure 2, panels A5 and A6). The detailed information is shown in Table 1.

\begin{tabular}{|c|c|c|c|}
\hline Groups & PK/PD parameters & Interval (h) & MIC $(\mu \mathrm{g} / \mathrm{mL})$ \\
\hline $\mathrm{A} 1(\mathrm{~N}=2)$ & $\mathrm{T}>\mathrm{MIC}_{99} \%=0$ & 24 & $\begin{array}{c}\text { Total } 4 \text { cages, } \\
\text { no increase }\end{array}$ \\
\hline $\mathrm{A} 2(\mathrm{~N}=2)$ & $\mathrm{T}>\mathrm{MPC} \%=100 \%$ & 24 & $\begin{array}{c}\text { Total } 3 \text { cages, } \\
\text { no increase }\end{array}$ \\
\hline \multirow[t]{3}{*}{ A3 $(N=3)$} & $\mathrm{T}>\mathrm{MIC}_{99} \%=25 \%$ & \multirow[t]{3}{*}{24} & \multirow{3}{*}{$\begin{array}{c}\text { 1/total } 6 \text { cages, } \\
\text { increased to } 0.512\end{array}$} \\
\hline & $\mathrm{T}>\mathrm{MPC} \%=0$ & & \\
\hline & $\mathrm{T}_{\mathrm{MSW}} \%=25 \%$ & & \\
\hline \multirow[t]{3}{*}{ A4 $(N=3)$} & $\mathrm{T}>\mathrm{MIC}_{99} \%=100 \%$ & \multirow[t]{3}{*}{24} & \multirow{3}{*}{$\begin{array}{c}\text { 1/total } 5 \text { cages, } \\
\text { increased to } 0.512\end{array}$} \\
\hline & $\mathrm{T}>\mathrm{MPC} \%=50 \%$ & & \\
\hline & $\mathrm{T}_{\mathrm{MSW}} \%=50 \%$ & & \\
\hline \multirow{3}{*}{$\begin{array}{c}A 5(N=2) \\
\& A 6(N=3)\end{array}$} & $\mathrm{T}>\mathrm{MIC}_{99} \%=100 \%$ & \multirow[t]{3}{*}{24} & \multirow{3}{*}{$\begin{array}{c}\text { 8/total } 8 \text { cages, } \\
\text { increased to } 2.048\end{array}$} \\
\hline & $\mathrm{T}>\mathrm{MPC} \% \leq 25 \%$ & & \\
\hline & $75 \% \leq T_{M S W} \% \leq 100 \%$ & & \\
\hline \multirow{3}{*}{$\begin{array}{c}A 7(N=3) \\
\& A 8(N=2)\end{array}$} & $\mathrm{T}>\mathrm{MIC}_{99} \%=100 \%$ & \multirow[t]{3}{*}{12} & \multirow{3}{*}{$\begin{array}{c}\text { 8/total 8cages, } \\
\text { increased to } 0.512\end{array}$} \\
\hline & $\mathrm{T}>\mathrm{MPC} \%=0$ & & \\
\hline & $\mathrm{T}_{\mathrm{MSW}} \%=100 \%$ & & \\
\hline
\end{tabular}

Cefquinome PK/PD values were determined from tissue cage fluids using total drug concentrations. $\mathrm{N}$ is the animal number per group.
The fraction of mutants dramatically increased $\left(>10^{4}\right.$ fold) when drug concentrations fell inside the selection window. And there was no difference no matter whether the concentration partly or wholly dropped into the MSW (Figure 2, panels C3-C8). Overall, these data have shown that the selection window boundaries determined by agar plate assays fit well with results obtained in vivo in piglets for cefquinome.

\section{Correlation of PK/PD indices with mutant enrichment and amplification}

$\mathrm{PK} / \mathrm{PD}$ indices, such as $\mathrm{AUC}_{24 \mathrm{~h}} / \mathrm{MIC}_{99}$ (where $\mathrm{AUC}_{24 \mathrm{~h}}$ is the area under the drug concentration time curve in a $24 \mathrm{~h}$ interval) and time above the $\mathrm{MIC}_{99}$, provide an empirical way to relate antimicrobial dose to favorable treatment effect for bactericidal agents. Relationships between PK/PD indices, determined as steady-state values after the fifth dose, and lost of susceptibility are shown in Table 2. For cephalosporin, $\mathrm{T}>\mathrm{MIC}_{99}$ is the index most commonly associated with restricting susceptible cell growth. Only 1 of 10 tissue-cages lost susceptibility when $\mathrm{T}>\mathrm{MIC}_{99} \leq 6 \mathrm{~h}$ or $\mathrm{T}>\mathrm{MIC}_{99} \% \leq 25 \%$ (Table 2 and Figure 2, panels $\mathrm{A} 1$ and $\mathrm{A} 3$ ). $\mathrm{T}>\mathrm{MPC}$ is probably the appropriate parameter for the upper boundary of the selection window. Only 1 of 8 tissue-cages was lost susceptibility when $\mathrm{T}>\mathrm{MPC} \geq 12 \mathrm{~h}$ or $\mathrm{T}>\mathrm{MPC} \% \geq 50 \%$ (Table 2 and Figure 2, panels A2 and A4). Loss of bacterial susceptibility occurred in 16 of 16 tissue-cages (8 for $24 \mathrm{~h}$ interval and 8 for $12 \mathrm{~h}$ interval) when $\mathrm{T}_{\mathrm{MSW}} \%$ was between $25 \%$ and $100 \%$, with $\mathrm{T}>\mathrm{MPC} \% \leq 25 \%$ simultaneously (Table 2 and Figure 2, panels A5-A8).

Other PK/PD indices also showed statistically significant $(\mathrm{P}<0.05)$ correlations with the selection of resistance (Table 2). When $\mathrm{AUC}_{24} \mathrm{~h} / \mathrm{MIC}_{99}$ and $\mathrm{AUC}_{24} \mathrm{~h} / \mathrm{MPC}$ were considered, the mutant selection window extended from $32.84 \mathrm{~h}$ to $125.64 \mathrm{~h}$ and from $12.83 \mathrm{~h}$ to $49.09 \mathrm{~h}$, respectively. In another example, the selection window extended from 1.32 to 4.26 and from 0.52 to 1.66 , respectively, when maximum concentration $\mathrm{C}_{\max } / \mathrm{MIC}_{99}$ and $\mathrm{C}_{\max } / \mathrm{MPC}$ were considered.

\section{Discussion}

Antimicrobial resistance becomes an increasingly serious problem that is likely to require attention at many levels [2]. Issues concerning dosing are addressed by the mutant selection window hypothesis [18]. The fundamental difference between the traditional MIC-based strategies and the MPC-based approach is that the former requires bacteria to acquire only 1 mutation for growth in the presence of drug, whereas the latter requires 2 or more [19].

Considering the boundaries of the selection window, it need to be predictable on the basis of data obtained by clinical microbiological laboratories. Previous work has shown that static agar plate values of $\mathrm{MIC}_{99}$ and MPC 
Table 2 Correlation of pharmacokinetic/ pharmacodynamics (PK/PD) parameters with selection of resistance

\begin{tabular}{|c|c|c|}
\hline $\begin{array}{l}\text { PK/PD index, } \\
\text { value }^{\mathrm{a}}\end{array}$ & $\begin{array}{l}\text { Fraction of tissue-cages with resistant } \\
\text { bacteria (mutant/total) }\end{array}$ & $P^{b}$ \\
\hline \multicolumn{3}{|l|}{$\mathrm{T}>\mathrm{MIC}_{99}$} \\
\hline$\leq 25 \%$ & $1 / 10$ & 0.625 \\
\hline$>25 \%$ & $17 / 24$ & 0.003 \\
\hline \multicolumn{3}{|l|}{$\mathrm{T}>\mathrm{MPC}$} \\
\hline$<50 \%$ & $17 / 26$ & 0.006 \\
\hline$\geq 50 \%$ & $1 / 8$ & 0.400 \\
\hline \multicolumn{3}{|c|}{$\mathrm{AUC}_{24} \mathrm{~h} / \mathrm{MIC}_{99}(\mathrm{~h})$} \\
\hline$\leq 32.84$ & $1 / 8$ & 0.571 \\
\hline $32.84-125.64$ & $16 / 20$ & 0.001 \\
\hline$\geq 125.64$ & $1 / 6$ & 0.500 \\
\hline \multicolumn{3}{|l|}{$\mathrm{AUC}_{24 \mathrm{~h}} / \mathrm{MPC}(\mathrm{h})$} \\
\hline$\leq 12.83$ & $1 / 8$ & 0.571 \\
\hline $12.83-49.09$ & $16 / 20$ & 0.001 \\
\hline$>49.09$ & $1 / 6$ & 0.500 \\
\hline \multicolumn{3}{|l|}{$\mathrm{C}_{\max } / \mathrm{MIC}_{99}$} \\
\hline$\leq 1.32$ & $1 / 9$ & 0.600 \\
\hline $1.32-4.26$ & $16 / 18$ & 0.0002 \\
\hline$\geq 4.26$ & $1 / 7$ & 0.539 \\
\hline \multicolumn{3}{|l|}{$\mathrm{C}_{\max } / \mathrm{MPC}$} \\
\hline$\leq 0.52$ & $1 / 9$ & 0.600 \\
\hline $0.52-1.66$ & $16 / 18$ & 0.0002 \\
\hline$\geq 1.66$ & $1 / 7$ & 0.539 \\
\hline
\end{tabular}

All PK/PD parameters were determined using total drug concentrations in tissue cage fluid. Total 34 tissue cages were analyzed and 2 tissue cages excluded because of bacterial pollution.

${ }^{a}$ Tine in the window $\left(T_{m s w}\right)$ is not presented in the table because it fell into 2 categories.

${ }^{\mathrm{b}} \mathrm{P}$ values were calculated by Fishers exact test, with a set of 3 infected but untreated piglets (6 tissue-cages) used as a control. High values indicate no difference with the control.

of fluoroquinolones fit well with selection window boundaries obtained in in vitro models $[4,6,8,20]$. The data in Figure 2 demonstrate that agar plate determinations of $\mathrm{MIC}_{99}$ and MPC fit well with the boundaries of the selection window seen in vivo at the site of infection for cefquinome.

In $\mathrm{PK} / \mathrm{PD}$ model, the $\mathrm{T}>\mathrm{MIC}$ (for time-dependent drugs) and $\mathrm{AUC}_{24} \mathrm{~h} / \mathrm{MIC}$ (for concentration-dependent drugs) can be used empirically to predict favorable effect when susceptible populations are considered [21]. Herein, the $\mathrm{T}>\mathrm{MIC}_{99}$ (for time-dependent drugs) or $\mathrm{AUC}_{24} \mathrm{~h} /$ $\mathrm{MIC}_{99}$ (for concentration-dependent drugs) can be used to define the lower boundary of the selection window in $\mathrm{PK} / \mathrm{PD}$ combined with MSW model. For the upper boundary of the window, as the MPC is the MIC of the least-susceptible single-step mutant, $\mathrm{T}>\mathrm{MPC}$ or $\mathrm{AUC}_{24 \mathrm{~h}}$ / MPC probably is the appropriate parameter [22]. An in vitro study of $E$. coli treated with ciprofloxacin also argued for the use of $\mathrm{AUC}_{24} \mathrm{~h} / \mathrm{MPC}$. Other PK/PD indices such as $\mathrm{C}_{\max } / \mathrm{MIC}_{99}, \mathrm{C}_{\max } / \mathrm{MPC}$, and time in the window $\left(\mathrm{T}_{\mathrm{MSW}} \%\right)$ also showed a statistically significant $(\mathrm{P}<0.05)$ correlation with the selection of resistance.

In present study, a correction is required when concentrations are high enough to kill the resistant (the cefquinome concentration needed to exceed the MPC for over half the dosing period to restrict the recovery of mutants). Keeping antimicrobial concentrations above the MPC $>12 \mathrm{~h}$ ( $>>\mathrm{MPC} \%>50 \%$ ) or $\mathrm{AUC}_{24} \mathrm{~h} / \mathrm{MPC}>49.09 \mathrm{~h}$ is a straightforward way to restrict the acquisition of resistance in this study. However, it is still complicated that what concentrations made the susceptible strains acquired resistance inside the window. In previous investigation, concentrations at the center of the window were suitable for selecting a double mutant in an in vitro model [23]. In present piglet/perforated-tissue-cage system, the drug concentration needed to be inside the window for $\geq 75 \%$ of the interval for enrichment mutants when those concentrations fluctuated above and below the MPC. When the concentrations fluctuated above and below the $\mathrm{MIC}_{99}$, they needed to be inside the window for only $25 \%$ of the interval. This difference probably results from: (1) more abundant preexisting resistant mutant subpopulations being able to survive and

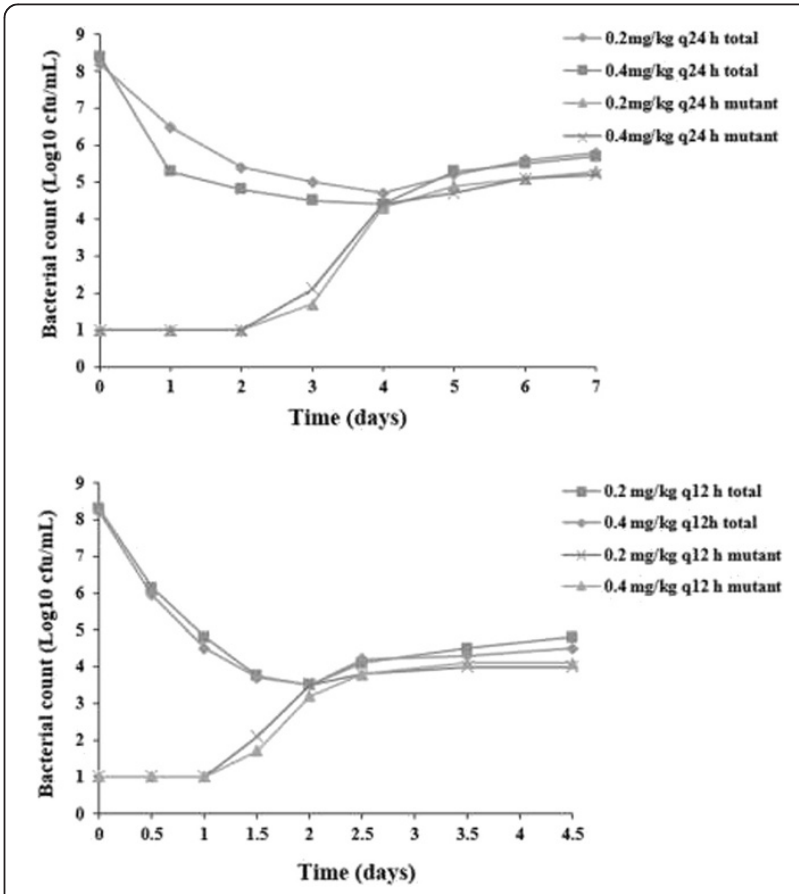

Figure 3 Effect of cefquinome exposure on recovery of total and resistant bacteria. Concentrations of total bacteria and resistant mutants were determined in aliquots of tissue-cage fluid obtained at the indicated time points after the initiation of treatment. Representative two examples (one piglet each dose regimen) are shown for piglets in which the cefquinome concentration was inside the mutant selection window, as determined in Figure 2. 
propagate near the bottom of the window; (2) the killing of some mutants when drug concentrations are close to the top of the window; (3) the organism have a better growth fitness at a low concentration than a high condition [22].

The fraction of mutants can increase either by mutant amplification (outgrowth of mutant cells) or by mutant enrichment (killing of susceptible cells). To distinguish these situation, we determined the absolute number both of total and resistant bacteria. When drug concentrations were inside the selection window, the total population size decreased and then gradually increased. However, the mutant numbers were initially constant, indicating that a fractional increase may result from preferential killing of susceptible cells. After several times of administration, amplification of mutants was observed at last (Figure 3). Thus, the selection of cefquinome-resistant mutants in vivo probably arose from both mutant amplification (outgrowth of mutant cells) and mutant enrichment (killing of susceptible cells).

Beta-lactam antibiotics, including penicillins, cephalosporins and carbapenems, are widely used not only in human but also in vet clinic. Production of beta-lactamase is one of major resistance mechanisms in gram-negative bacteria, which mostly refers to extended-spectrum beta-lactamases (ESBLs) existing largely in microorganisms of the family Enterobacteriaceae [24]. It was complicated to confirm the mechanism of acquisition resistant genes for sensitive strains exposure of antimicrobial agents, such as chromosome gene mutant and plasmid acquisition. The present data could not display how the resistant property was produced by E. coli ATCC 25922. More molecular technique, the PCR of target gene, the PFGE of original strain and mutants, and plasmid profiles analysis at least, should be applied to determine the mutant gene which caused bacterial resistance. Those are the mainly study purposes of the next task in laboratory animals.

\section{Conclusions}

In conclusion, the data in Figure 2 demonstrate that the mutant selection window agar plate determinations fit well with the piglets infected with E. coli ATCC 25922 of cefquinome treatment in vivo. Because agar plate assays are routine in clinical laboratories, implementation of selection window dosing strategy is feasible. The next steps for the tissue-cage model are to obtain more data to confirm the boundary of MSW. For example, more virulent strains should be used to allow bacterial populations to reach $10^{10}$ cells by in vivo growth from a smaller inoculum in further study.

\section{Abbreviations}

MSW: Mutant selection window; E.coli: Escherichia coli; MIC: Minimum inhibitory concentration; MPC: Mutant prevention concentration; PK: Pharmacokinetics; PD: Pharmacodynamics; AUC: Area under the curve; CFU: Colony forming unit; ATCC: American type culture collection;
NSAID: Non-steroidal anti-inflammatory drug; HPLC: High performance liquid chromatography; MS: Mass spectrometry; LLOQ: Lower limit of quantification; CV: Coefficients of variability; CLSI: Clinical and laboratory standards institute; ESBLs: Extended-spectrum beta-lactamases; PCR: Polymerase chain reaction; PFGE: Pulsed field gel electrophoresis.

\section{Competing interests}

The authors declare that they have no competing interests.

\section{Authors contributions}

Designed and conducted the experiment: HD; BZ. Animal management health and welfare: XG; YL; XL. Collected and analysis samples: BZ; MG; NZ; XS. Analysis data: BZ. Drafted the manuscript: BZ. All authors read and approved the final manuscript

\section{Acknowledgements}

Hebei Yuanzheng Pharmaceutical Corporation supplied the cefquinome sulphate injection used in this study. The corporation played no role in the study. This paper is supported by the Natural Science Foundation of China (Grant No. 31172366) and 973 Program under Grant No. 2013CB127200/ 2013 CB127203.

Received: 27 August 2014 Accepted: 8 December 2014

Published online: 16 December 2014

\section{References}

1. Cizman M: The use and resistance to antibiotics in the community. Int J Antimicrob Ag 2003, 21:297 307.

2. Levy SB, Marshall B: Antibacterial resistance worldwide: causes, challenges, and response. Nat Med 2004, 10:S122 S129.

3. Stratton C: Dead bugs dont mutate: susceptibility issues in the emergence of bacteria resistance. Emerg Infect Dis 2003, 9:10 16

4. Cui J, Liu Y, Wang R, Tong W, Drlica K, Zhao X: The mutant selection window in rabbits infected with Staphylococcus aureus. J Infect Dis 2006, 194:1601 1608.

5. Sindelar G, Zhao X, Liew A, Dong Y, Lu T, Zhou J, Domagala J, Drlica K: Mutant prevention concentration as a measure of fluoroquinolone potency against Mycobacteria. Antimicrob Agents Ch 2000, 44:3337 3343.

6. Firsov AA, Vostrov SN, Lubenko IY, Drlica K, Portnoy YA, Zinner SH: In vitro pharmacodynamics evaluation of the mutant selection window hypothesis: four fluoroquinolones against Staphylococcus aureus. Antimicrob Agents Ch 2003, 47:1604 1613.

7. Liang B, Bai N, Cai Y, Wang R, Drlica K, Zhao X: Mutant prevention concentration-based Pharmacokinetic/Pharmacodynamic indices as dosing targets for suppressing the enrichment of levofloxacin-resistant subpopulations of Staphylococcus aureus. Antimicrob Agents Ch 2011, 55:2409 2412

8. Zinner S, Lubenko I, Gilbert D, Simmons K, Zhao X, Drlica K, Firsov AA: Emergence of resistant Streptococus pneumonia in an in vitro dynamic model that simulates moxifloxacin concentration in and out of the mutant selection window: related changes in susceptibility, resistance frequency, and bacterial killing. J Antimicrob Chemoth 2003, 2003(52):616 622.

9. Zinner SH, Gilbert D, Lubenko IY, Greer K, Firsov AA: Selection of Linezolidresistant Enterococcus faecium in an in vitro dynamic model: protective effect of doxycycline. J Antimicrob Chemoth 2008, 61:629 635.

10. Ferran AA, Kesteman AS, Toutain PL, Bousquet-Mlou A: Pharmacokintic/ Pharmacodynamic analysis of the influence of inoculum size on the selection of resistance in Escherichia coli by a quinolone in a mouse thigh bacterial infection model. Antimicrob Agents Ch 2009, 53:3384 3390.

11. Zhu Y, Hu L, Mei Q, Cheng J, Liu Y, Ye Y, Li J: Testing the mutant selection window in rabbits infected with methicillin-resistant Staphylococcus aureus exposed to vancomycin. J Antimicrob Chemoth 2012, 67:2700 2706.

12. Committee for Veterinary Medical Products. Cefquinome. Summary report. EMEA/MRL/005/95. European Agency for the evaluation of Medicinal Products 1995. London, UK. http://www.ema.europa.eu/docs/en GB/ document_library/Maximum_Residue_Lmit___Report/2009/11/ WC500011877.pdf accessed 12 September 2010.

13. Committee for Veterinary Medical Products. Cefquinome (Extension to Pigs). Summary Report (2). EMEA/MRL/545/99-FINAL. European Agency for the Evaluation of Medicinal Products 1999, London, UK. http://www.ema.europa. 
eu/docs/en_GB/document_library/Maximum_Residue_Limits___Report/ 2009/11/WC500011890.pdf accessed 12 September 2010.

14. Scott D, Kling J, Gest G: Characterization of Staphylococcus aureus isolates from patients with toxic shock syndrome, using polyethylene infection chambers in rabbits. Infect Immun 1983, 39:383 387.

15. Lu T, Zhao X, Li X, Hansen G, Blondeau J: Effect of chloramphenicol erythromycin, moxifloxacin, penicillin, and tetracycline concentration on the recovery of resistant mutants of Mycobacterium smegmatis and Staphylococcus aureus. J Antimicrob Chemoth 2003, 52:61 64.

16. Sidhu P, Aliabadi F, Andrews M, Lees P: Tissue chamber model of acute inflammation in farm animal species. Res Vet Sci 2003, 74:439 446.

17. Watts JL, Shryock TR, Apley M, Brown SD, Gray JT, Heine H, Hunter RP, Mevius DJ, Paich MG, Silley P, Zurenko GE: Performance standards for antimicrobial disk and dilution susceptibility tests for bacteria isolated from animals; approved standard third edition. CLSI 2008, 28:1 33.

18. Mouton JW, Dudley MN, Cars O, Derendorf H, Drusano GL: Standardization of pharmacokinetic/pharmacodynamics (PK/PD) terminology of anti-infective drugs: an update. J Antimicrob Chemoth 2005, 55:601 607.

19. Drlica $K$ : The Mutant selection window and antimicrobial resistance. J Antimicrob Chemoth 2003, 52:11 17.

20. Drlica K, Zhao X: Mutant selection window hypothesis updated. Clin Infect Dis 2007, 44:681 688

21. Zhao X, Drlica K: Restricting the selection of antibiotic-resistant mutants: measurement and potential use of the mutant selection window. $J$ Infect Dis 2002, 185:561 565.

22. Blondeau JM: New concepts in antimicrobial susceptibility testing: the mutant prevention concentration and mutant selection window approach. Vet Dermatol 2009, 20:383 396

23. Campion JJ, McNamara PJ, Evans ME: Evolution of ciprofloxacin-resistant Staphylococcus aureus in In Vitro pharmacokinetic environments. Antimicrob Agents Ch 2004, 48:4733 4744.

24. Nikonorow E, Baraniak A, Gniadkowski M: Beta-lactamase-mediated resistance in Enterobacteriaceae. Postep Mikrobiol 2013, 52:261 271

doi:10.1186/s12917-014-0297-1

Cite this article as: Zhang et al.: In vivo evaluation of mutant selection window of cefquinome against Escherichia coli in piglet tissue-cage model. BMC Veterinary Research 2014 10:297.

\section{Submit your next manuscript to BioMed Central and take full advantage of:}

$凶$ Convenient online submission

$\otimes$ Thorough peer review

$\nabla$ No space constraints or color $\nabla$ gure charges

QImmediate publication on acceptance

\Inclusion in PubMed, CAS, Scopus and Google Scholar

$\otimes$ Research which is freely available for redistribution 